\title{
Electrical properties of pyrochlore-type silver tantalate and fluorite-type silver niobate
}

\author{
Withanage ISURU UDAKARA WITHANAGE ${ }^{1}$, Nobuhiro KUMADA ${ }^{1, \dagger}$, Takahiro TAKEI ${ }^{1}$, \\ Sayaka YANAGIDA ${ }^{1}$, Kiyoharu TADANAGA ${ }^{2}$, Akira MIURA ${ }^{2}$, \\ Nataly Carolina ROSERO-NAVARRO ${ }^{2}$ and Masaki AZUMA ${ }^{3}$ \\ ${ }^{1}$ Center for Crystal Science and Technology, University of Yamanashi, 7-32 Miyamae, Kofu 400-8511, Japan \\ ${ }^{2}$ Division of Applied Chemistry, Faculty of Engineering, Hokkaido University, Sapporo 060-8628, Japan \\ ${ }^{3}$ Laboratory for Materials and Structures, Tokyo Institute of Technology, 4259 Nagatsuta, Midori, Yokohama 226-8503, Japan
}

Pyrochlore-type silver tantalate, $\mathrm{Ag}_{0.93} \mathrm{TaO}_{2.97} \cdot 0.94 \mathrm{H}_{2} \mathrm{O}$ (AT), and fluorite-type silver niobate $\mathrm{Ag}_{0.41} \mathrm{Nb}_{0.59} \mathrm{O}_{1.68}$ (AN), were prepared by ion-exchange reactions and their ion conductivities were measured from 25 to $240^{\circ} \mathrm{C}$. The total conductivities (ionic + electrical) at $240^{\circ} \mathrm{C}$ of $\mathrm{AT}$ and $\mathrm{AN}$ reached $4.00 \times 10^{-3}$ and $9.03 \times 10^{-4} \mathrm{~S} / \mathrm{cm}$, respectively. The activation energy of $\mathrm{AT}$ was $0.61 \mathrm{eV}$ and $\mathrm{AN}$ showed non-linear behavior with activation energies of $0.52 \mathrm{eV}$ at temperatures less than $120^{\circ} \mathrm{C}$ and $0.33 \mathrm{eV}$ at temperatures greater than $120^{\circ} \mathrm{C}$. The crystal structures of $\mathrm{AT}$ and $\mathrm{AN}$ were maintained from 25 to $240^{\circ} \mathrm{C}$.

(C2020 The Ceramic Society of Japan. All rights reserved.

Key-words : Pyrochlore-type, lonic conductivity, fluorite-type

\section{Introduction}

Recently, Ag-based oxides $\mathrm{AgMO}_{3}$ (M: Nb and Ta), ${ }^{1)-3)}$ $\mathrm{AgVO}_{3},{ }^{4)} \mathrm{Ag}_{3} \mathrm{PO}_{4},{ }^{5)} \mathrm{AgGaO}_{2},{ }^{6)}$ etc., have been receiving attention because of their photocatalytic activity for water splitting as well as for the decomposition of organic compounds in water. The $\operatorname{AgMO}_{3}(\mathrm{M}: \mathrm{Nb}$ and $\mathrm{Ta})$ compounds have various properties like ion exchange, ${ }^{3), 7)}$ ionic conductivity, ${ }^{8)}$ and ferroelectricity, ${ }^{9)}$ as well as visiblelight-driven photocatalysis. After the discovery of the superionic conductivity of AgI-containing solid electrolytes, the ionic conductivities of Ag-based compounds have been extensively investigated. ${ }^{10)}$ AgI shows temperaturedependent structural transitions; at low temperatures ( $\left.147^{\circ} \mathrm{C}\right) \beta / \gamma$-AgI transform to $\alpha$-AgI, owing to the fastion conductivity. ${ }^{11), 12)}$ However, its application as a solid electrolyte is limited by its low ionic conductivity at room temperature. To ensure its technical applicability, a solid electrolyte must show high ion-mobility at low temperatures. Recently, the ionic conductivity of solid electrolytes has gained much attention for their applications in solidoxide fuel-cells, ${ }^{13), 14)}$ gas sensors, ${ }^{15)}$ oxygen separation membranes, ${ }^{16)}$ batteries, ${ }^{17)}$ and catalysts. ${ }^{18)}$ Much effort has been devoted to obtaining stable structures with high ionic conductivity at low operating temperatures.

Our previous study successfully demonstrated the synthesis of pyrochlore-type $\mathrm{Ag}_{0.93} \mathrm{TaO}_{2.97} \cdot 0.94 \mathrm{H}_{2} \mathrm{O}$ (AT) and

\footnotetext{
Corresponding author: N. Kumada; E-mail: kumada@ yamanashi.ac.jp
}

fluorite-type silver niobate $\mathrm{Ag}_{0.41} \mathrm{Nb}_{0.59} \mathrm{O}_{1.68}$ (AN) by ionexchange reactions. ${ }^{3)}$ The pyrochlore-type compound is represented by the general formula $\mathrm{A}_{2} \mathrm{~B}_{2} \mathrm{O}_{6} \mathrm{O}$ and it is considered as a superstructure of the fluorite-type structure which has the general formula $\mathrm{AO}_{2}$. A larger sized $\mathrm{A}$ cation occupied at $16 d$ site is generally an alkali metal, an alkaline earth metal or a rare earth metal, ${ }^{19), 20)}$ a B cation occupy at $16 c$ sites is a transition metal while $\mathrm{O}$ and $\mathrm{O}^{\prime}$ occupy at $48 f$ and $8 b$ sites respectively. ${ }^{21), 22)}$ The ordered pyrochlore structure can be transformed into the disordered fluorite structure by decreasing the A site cation size $^{23)}$ which transforms to a face centered cubic system. Furthermore, the tunnel structure of the pyrochlore-type compound and the related fluorite structure provide the possibility of diffusion pathways for the silver ions migration, facilitating the ionic conductivity. In this work, we have successfully investigated the total conductivity of AT and $\mathrm{AN}$ by $\mathrm{AC}$ impedance measurements as a function of temperature.

\section{Experiments}

Pyrochlore-type silver tantalate, AT and fluorite-type silver niobate AN were obtained by the reaction of pyrochlore-type $\left(\mathrm{K}_{0.56} \mathrm{H}_{0.44}\right) \mathrm{TaO}_{3} \cdot 1.14 \mathrm{H}_{2} \mathrm{O} \quad$ and $\left(\mathrm{K}_{0.73} \mathrm{H}_{0.27}\right) \mathrm{NbO}_{3} \cdot 1.72 \mathrm{H}_{2} \mathrm{O}$, respectively, with excess molten $\mathrm{AgNO}_{3}$ at $300^{\circ} \mathrm{C}$ for $6 \mathrm{~h} .{ }^{3)}$ In-situ high temperature synchrotron X-ray powder diffraction data were collected at the SPring- 8 facility in Hyogo Japan, BL02B2 beam line with wavelength $\lambda=0.413853 \AA(1 \AA=0.1 \mathrm{~nm})$, and the samples were loaded in a quartz capillary with a $0.2 \mathrm{~mm}$ 
diameter. The powder diffraction data were refined using the Rietveld method with the RIETAN-FP computer program. ${ }^{24)}$ The chemical compositions were determined by energy dispersive X-ray spectrometry and the weight losses by thermogravimetry (TG) curves. To measure the total conductivity, pellets $(10 \mathrm{~mm}$ diameter and $3-4 \mathrm{~mm}$ thick) of the pyrochlore and fluorite compounds were obtained at the high pressure of $4 \mathrm{GPa}(10 \mathrm{~min})$ using a cubic-anvil-type high-temperature high-pressure apparatus. The total conductivity was determined by AC impedance measurement, as a function of temperature, using an impedance analyzer (SI 1260, Solartron) over the frequency range of $1 \mathrm{~Hz}$ to $10 \mathrm{MHz}$. The electrodes were sputter-coated with gold on both sides of the pellet and connected with a platinum wire using Ag paste. These measurements were performed in the temperature range $25-240^{\circ} \mathrm{C}$ and the stabilization time before each data point was obtained was approximately $30 \mathrm{~min}$. The ZView software was used to analyze the spectra and calculate the ohmic resistance of the pellets.

\section{Results and discussion}

\subsection{Structure analysis}

The Rietveld refinement of AT and AN at room temper- ature shows in Fig. 1, gave reasonable $R$-factors $\left(R_{\mathrm{wp}}=\right.$ $6.61 \%, R_{\mathrm{p}}=5.11 \%$ for $\mathrm{AT}$ and $R_{\mathrm{wp}}=5.37 \%, R_{\mathrm{p}}=4.27 \%$ for $\mathrm{AN})$; the lattice parameters were determined to be $a=10.5375(2) \AA$ for AT and $a=5.2134(8) \AA$ for AN. The in-situ high-temperature synchrotron $\mathrm{X}$-ray diffraction (SXRD) patterns of AT and AN indicate no phase transition in the temperature range $25-240^{\circ} \mathrm{C}$, as shown in Fig. 2. These results imply that AT and AN exhibit good structural stability under air. The temperature dependences of the lattice parameters for AT (a) and AN (b) are shown in Fig. 3. As temperature increased, the lattice parameters of AT decreased, while an increase was observed for those of AN. This negative thermal expansion of AT was caused by the removal of water molecules on the hydrated pyrochlore-type structure. AT was hydrated and the thermogravimetric result in Fig. 4, showed a $4.77 \%$ mass loss. On the other hand AN had an anhydrate structure and it showed a very small mass loss $(0.81 \%)$ caused by the release of absorbed water. The thermal expansion coefficient for AN was calculated to be $0.09 \mathrm{~K}^{-1}$.

\subsection{Total conductivity of AT and AN}

Impedance spectra give, primarily, the AC impedance of the sample. Charge accumulation can take place within the
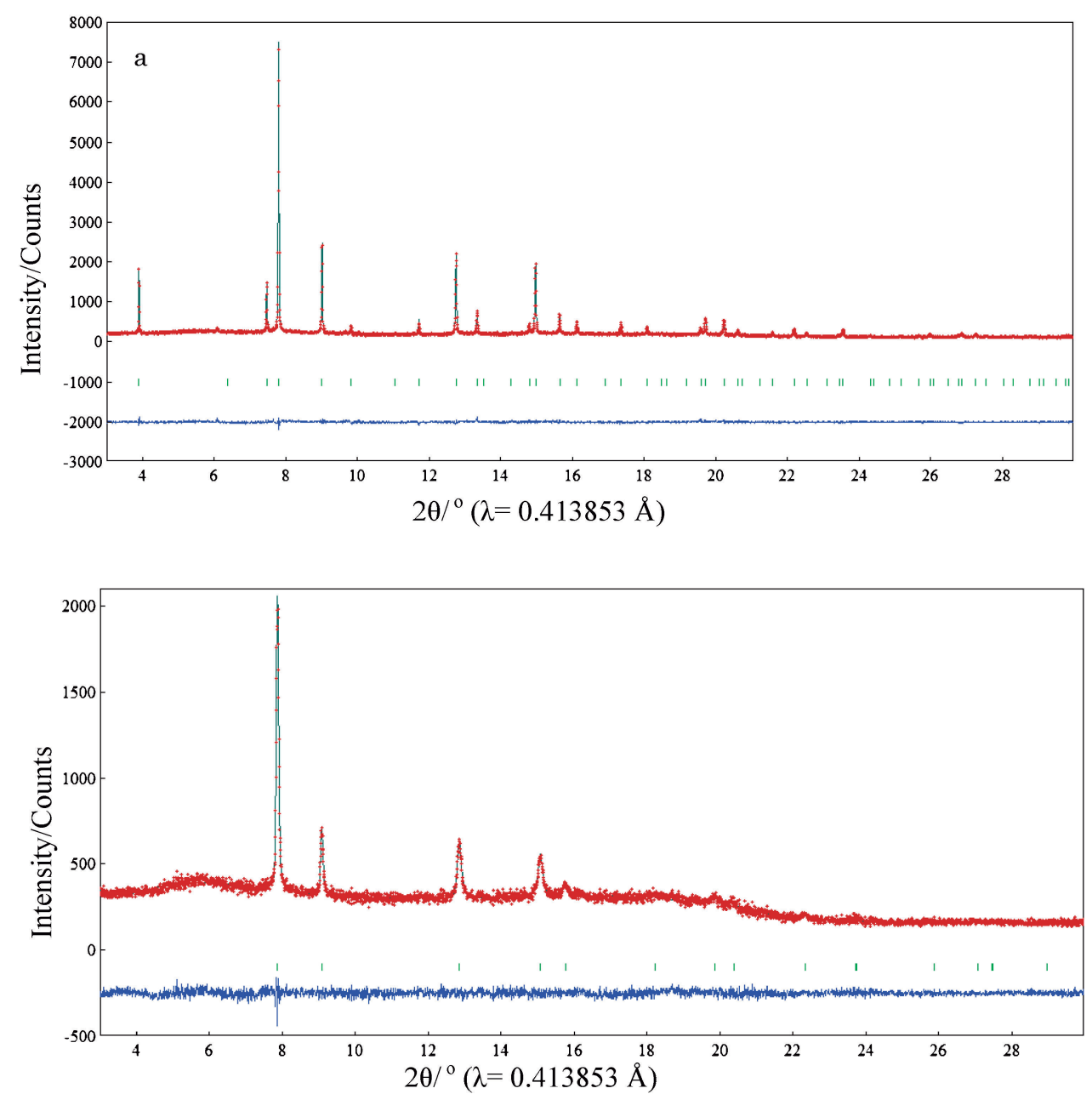

Fig. 1. Room temperature Rietveld refinement pattern of the synchrotron powder diffraction data for (a) $\mathrm{Ag}_{0.41} \mathrm{Nb}_{0.59} \mathrm{O}_{1.68}$ and (b) $\mathrm{Ag}_{0.93} \mathrm{TaO}_{2.97} \cdot 0.94 \mathrm{H}_{2} \mathrm{O}$. 

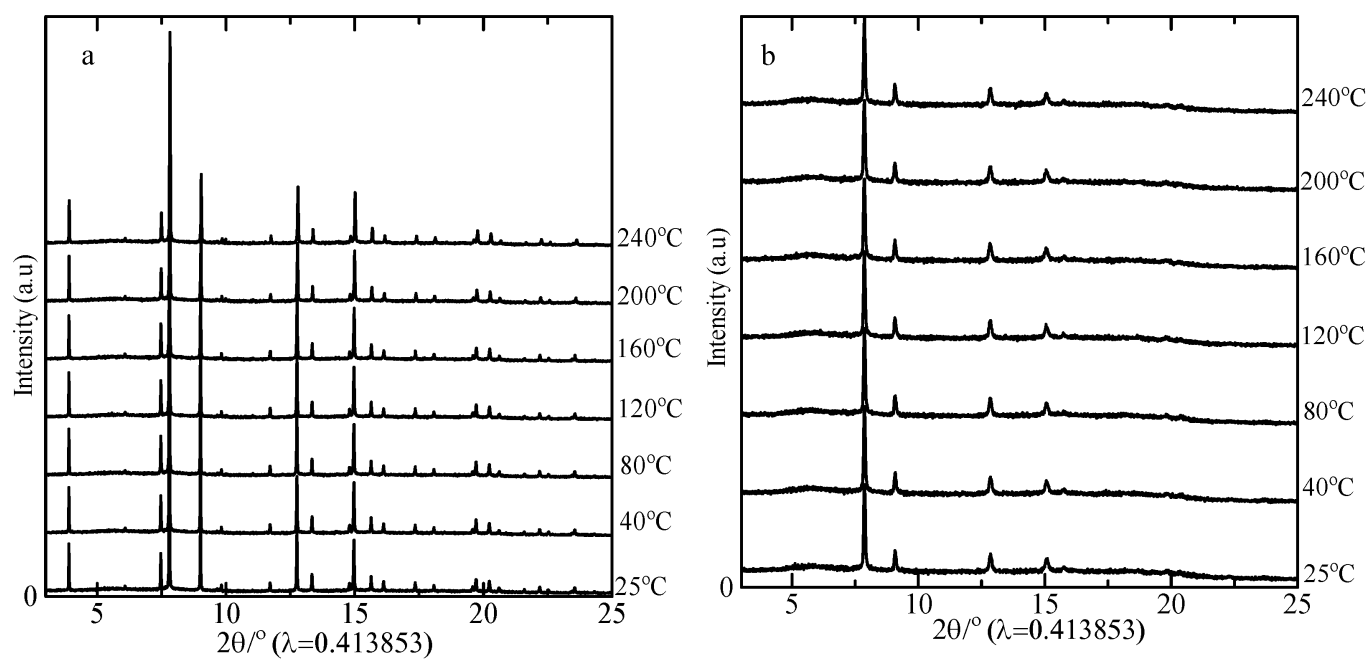

Fig. 2. In-situ high temperature SXRD patterns of the (a) AT and (b) AN.

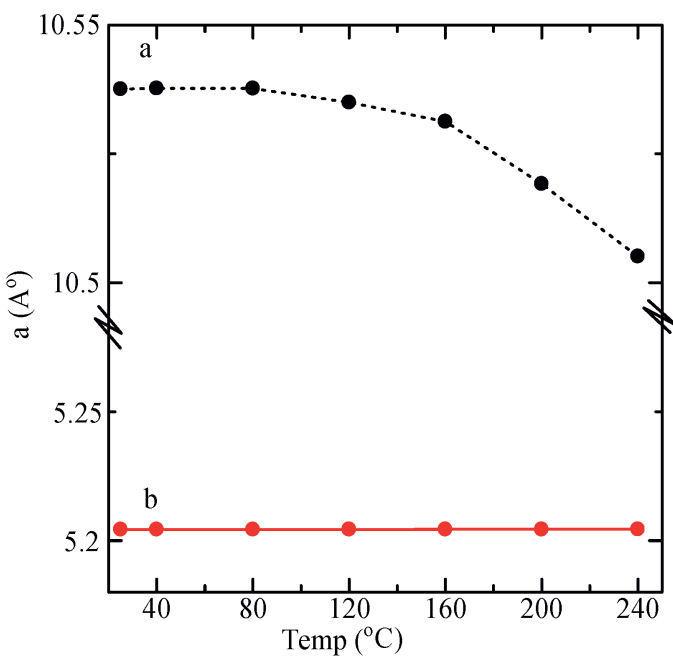

Fig. 3. Temperature dependence of lattice parameter for (a) AT and (b) AN. Circle size is larger than standard deviation.

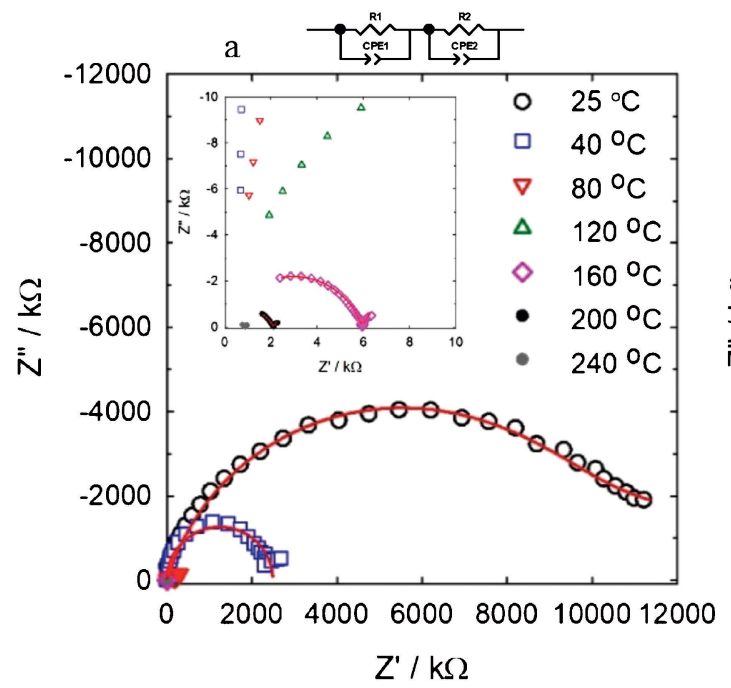

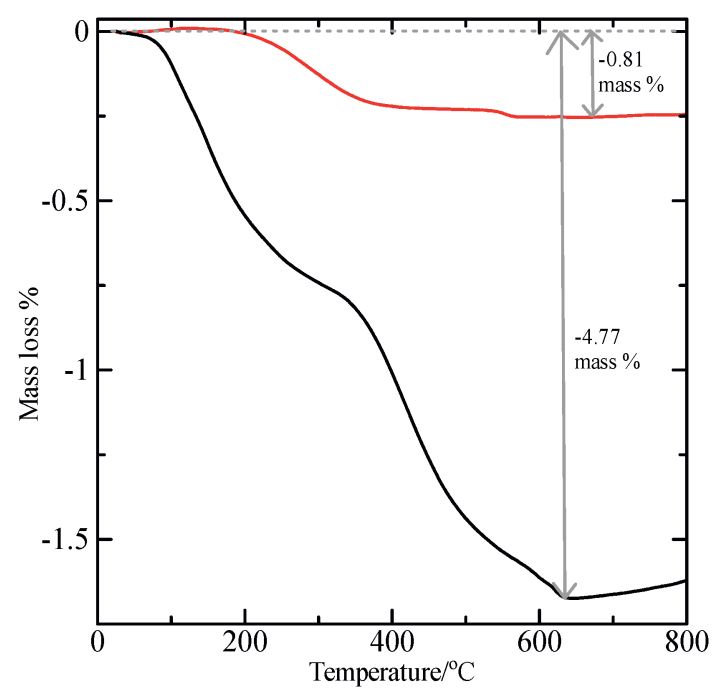

Fig. 4. TG curves of (a) AT (b) AN.

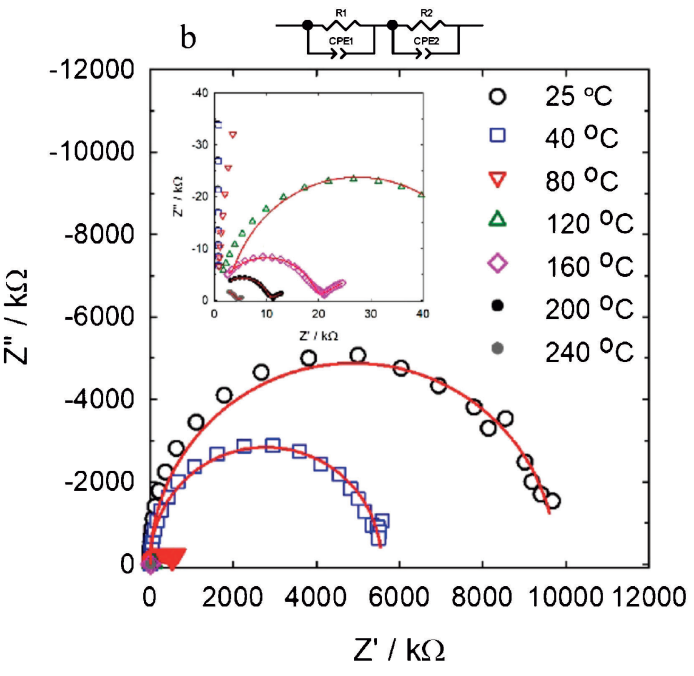

Fig. 5. Nyquist plot of (a) AT (b) AN.

bulk, in grain boundaries, or at the interfaces. Therefore, these crystalline samples are usually analogous to a series of two RC-parallel circuits. The overall representation of the AC impedance of $\mathrm{AT}$ and $\mathrm{AN}$ is contributed from grains and grain-boundaries, as suggested by the Nyquist plot shown in Fig. 5. The first semi-circle shows the total 


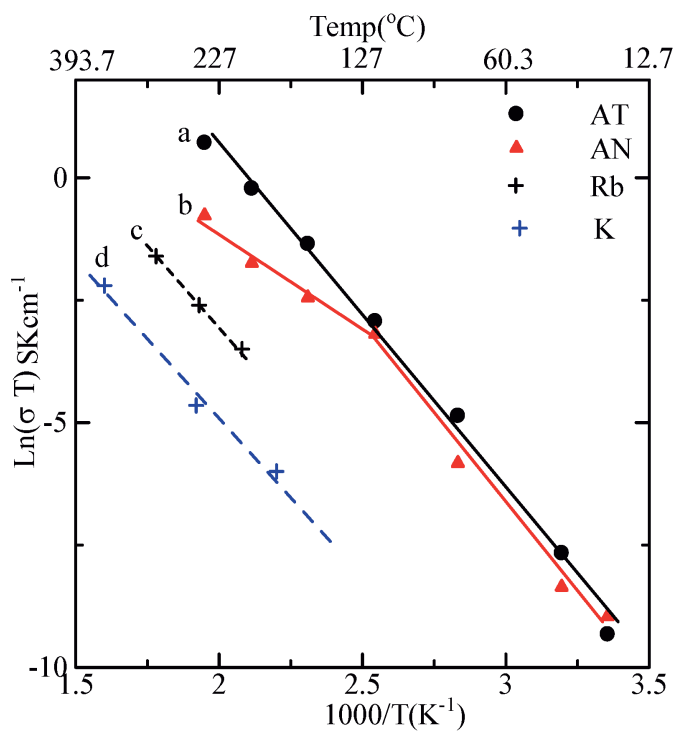

Fig. 6. Arrhenius plot of (a) AT (b) AN (c) $\mathrm{Rb}^{+}$in pyrochlore structure and (d) $\mathrm{K}^{+}$in pyrochlore structure.

conductivity of the sample. The intercept of the first semicircle with the real axis gives the total associated resistance $(R)$ and we consider the total resistance as the contribution from grains and grain-boundaries. The total conductivities of AT and AN reached $4.00 \times 10^{-3}$ and $9.03 \times 10^{-4}$ $\mathrm{S} / \mathrm{cm}$, respectively, at $240^{\circ} \mathrm{C}$. As shown in Fig. 6, the activation energy of AT was $0.61 \mathrm{eV}$ and AN showed nonlinear behavior with activation energies of $0.52 \mathrm{eV}$ at temperatures less than $120^{\circ} \mathrm{C}$ and $0.33 \mathrm{eV}$ at temperatures greater than $120^{\circ} \mathrm{C}$. The AN structure refinement shows the change in the atomic displacement parameter for $\mathrm{Ag}$ ions (B- 3.4 to $3.7 \AA^{2}$ ) in the range of $80-120^{\circ} \mathrm{C}$ and this atomic displacement facilitates the mobility of the silver ions and thus it may increase the total conductivity, reducing the activation energy. The Rietveld refinement of AN showed that the oxygen atom was statistically distributed in the 8c site, and $\mathrm{Ag}$ and $\mathrm{Nb}$ atoms randomly distributed in the $4 \mathrm{a}$ site. The bond valence sum (BVS) of $\mathrm{Ag} / \mathrm{Nb}$ was 3.00 and this value was close to 3.36 calculated from the ratio of $\mathrm{Ag} / \mathrm{Nb}$. The $\mathrm{B}$ value of oxygen atom was high and this suggested that oxygen atom contributes to total conductivity. In the case of AT Ag ions were distributed in the tunnel (16d site) of the pyrochlore-type structure and its $B$ value was high. The oxygen atom in the $8 \mathrm{~b}$ site was also in the tunnel and this oxygen was thought to belong to water molecule because mass loss was observed in the TG curve and the B value of oxygen ( $8 \mathrm{~b}$ ) was very high. The BVS of Ag was 1.04 and Ta was 5.26 respectively which were close to 1 and 5 , the actual values respectively. Table 1 lists in the refined structural parameters and BVS values. Furthermore, the corner shared $\mathrm{TaO}_{6}$ octahedral form a rigid network of AT tunnel structure, after the complete removal of water molecules from the crystal structure, it provides possible diffusion pathways for Ag-ions migration which was previously reported by Grins et al., ${ }^{25)}$ the $\mathrm{K}$ ion migration in pyrochlore type $\mathrm{K}_{1+x} \mathrm{Ta}_{1+x} \mathrm{~W}_{1-x} \mathrm{O}_{6} \cdot \mathrm{nH}_{2} \mathrm{O}$ compound. The activation ener-
Table 1. Room temperature crystallographic data and atomic parameters of $\mathrm{AT}$ and $\mathrm{AN}$

\begin{tabular}{lll}
\hline & $\mathrm{Ag}_{0.93} \mathrm{TaO}_{2.97} \cdot 0.94 \mathrm{H}_{2} \mathrm{O}$ & $\mathrm{Ag}_{0.41} \mathrm{Nb}_{0.59} \mathrm{O}_{1.68}$ \\
\hline Space group & $F d-3 m(\# 227)$ & $F m-3 m(\# 225)$ \\
$a(\AA)$ & $10.5375(2)$ & $5.2134(8)$ \\
Cell Volume $\left(\AA^{3}\right)$ & $1170.09(4)$ & $141.69(3)$ \\
$z$ & 16 & 4 \\
$R$-factor & $R_{\mathrm{wp}}=6.61 \% R_{\mathrm{p}}=5.11 \%$ & $R_{\mathrm{wp}}=5.37 \% R_{\mathrm{p}}=4.27 \%$ \\
& $R_{\mathrm{B}}=9.71 \% R_{\mathrm{F}}=6.25 \%$ & $R_{\mathrm{B}}=18.77 \% R_{\mathrm{F}}=13.35 \%$ \\
\hline
\end{tabular}

Atomic parameters $\mathrm{Ag}_{0.93} \mathrm{TaO}_{2.97} \cdot 0.94 \mathrm{H}_{2} \mathrm{O}$

\begin{tabular}{cccccccc}
\hline Atom & Site & $g$ & $x$ & $y$ & $z$ & $B\left(\AA^{2}\right)$ & BVS \\
\hline $\mathrm{Ta}$ & $16 \mathrm{c}$ & 1.036 & 0 & 0 & 0 & $1.7(5)$ & 5.26 \\
$\mathrm{Ag}$ & $16 \mathrm{~d}$ & 0.785 & $1 / 2$ & $1 / 2$ & $1 / 2$ & $6.6(2)$ & 1.04 \\
$\mathrm{O} 1$ & $48 \mathrm{f}$ & 1.000 & $0.335(1)$ & $1 / 8$ & $1 / 8$ & $1.0^{*}$ & \\
$\mathrm{O} 2$ & $8 \mathrm{~b}$ & 3.675 & 0.375 & $=x$ & $=x$ & $65.1(4)$ & \\
\hline
\end{tabular}

Atomic parameters $\mathrm{Ag}_{0.41} \mathrm{Nb}_{0.59} \mathrm{O}_{1.68}$

\begin{tabular}{cccccccc}
\hline Atom & Site & $g$ & $x$ & $y$ & $z$ & $B\left(\AA^{2}\right)$ & BVS \\
\hline $\mathrm{Ag} / \mathrm{Nb}$ & $4 \mathrm{a}$ & 1 & 0 & 0 & 0 & $3.0(1)$ & 3.00 \\
$\mathrm{O}$ & $8 \mathrm{c}$ & $2.3(4)$ & $1 / 4$ & $1 / 4$ & $1 / 4$ & $32(4)$ & \\
\hline
\end{tabular}

*: Fixed parameter.

gy of AT obtained was $0.61 \mathrm{eV}$ which is almost similar $(0.65 \mathrm{eV})$ to the data achieved in Grins et al. (Fig. 6). Furthermore Isasi et al. ${ }^{26)}$ reported that $\mathrm{Rb}$ ionic conductivity of defect pyrochlore type anhydrate structure (Fig. 6) which had shown $0.70 \mathrm{eV}$ activation energy. Although Rakesh et al. ${ }^{27)}$ has previously reported dielectric properties, to our knowledge there has been no reports of conductivity for pyrochlore-type silver tantalate and fluorite-type niobate structures. To compare with previously results we thought that the total conductivity of AN and AT is mostly correlated with migration of $\mathrm{Ag}^{+}$ions as well as oxygen ions or protons of the water molecules in the pyrochlore compounds. $^{28), 29)}$

\section{Conclusions}

Pyrochlore-type $\mathrm{Ag}_{0.93} \mathrm{TaO}_{2.97} \cdot 0.94 \mathrm{H}_{2} \mathrm{O}$ and fluoritetype $\mathrm{Ag}_{0.41} \mathrm{Nb}_{0.59} \mathrm{O}_{1.68}$ were prepared by ion-exchange reactions. Their structural and electrical properties were investigated. The impedance measurement of total conductivity, at $240^{\circ} \mathrm{C}$ reached the order of $10^{-3}$ and $10^{-4} \mathrm{~S} / \mathrm{cm}$ for tantalate and niobate, respectively. The calculated activation energy of AT was $0.61 \mathrm{eV}$ and AN showed nonlinear behavior with activation energies of $0.52 \mathrm{eV}$ at temperatures less than $120^{\circ} \mathrm{C}$ and $0.33 \mathrm{eV}$ at temperatures greater than $120^{\circ} \mathrm{C}$. The activation energy of $\mathrm{AN}$ was smaller than $\mathrm{K}$ ion migration in hydrated pyrochlore-type compound and $\mathrm{Rb}$ ion migration of dehydrated defect pyrochlore compound. The AN structure refinement shows the change in the atomic displacement parameter for $\mathrm{Ag}$ ions (B- 3.4 to $3.7 \AA^{2}$ ), in the range of $80-120^{\circ} \mathrm{C}$; this atomic displacement facilitates the mobility of $\mathrm{Ag}$ ions and, consequently, it may increase the total conductivity, reducing the activation energy.

\section{Reference}

1) H. Kato, H. Kobayashi and A. Kudo, J. Phys. Chem. B, 106, 12441-12447 (2002). 
2) D. Arney, C. Hardy, B. Greve and P. A. Maggard, J. Photoch. Photobio. A, 214, 54-60 (2010).

3) I. Withanage, N. Kumada, T. Takei, S. Yanagida, Y. Kuroiwa and C. Moriyoshi, J. Ceram. Soc. Jpn., 125, 776-778 (2017).

4) R. Konta, H. Kato, H. Kobayashi and A. Kudo, Phys. Chem., 5, 3061-3065 (2003).

5) X. Yang, H. Cui, Y. Li, J. Qin, R. Zhang and H. Tang, ACS Catal., 3, 363-369 (2013).

6) Y. Maruyama, H. Irie and K. Hashimoto, J. Phys. Chem. $B, 110,23274-23278$ (2006).

7) W. I. U. Withanage, S. Yanagida, T. Takei and N. Kumada, J. Ceram. Soc. Jpn., 126, 784-788 (2018).

8) R. Muduli, R. Pattanayak, S. Kumar, S. K. Kar, P. Kumar, S. Panigrahi and R. K. Panda, J. Alloy. Compd., 656, 33-44 (2016).

9) H. U. Khan and Y. Iqbal, J. Electron. Mater., 43, 35503558 (2014).

10) C. Tubandt and E. Lorenz, Z. Phys. Chem., 87, 513-542 (1914).

11) R. Makiura, T. Yonemura, T. Yamada, M. Yamauchi, R. Ikeda, H. Kitagawa, K. Kato and M. Takata, Nat. Mater., 8, 476-480 (2009).

12) M. Tatsumisago, Y. Shinkuma and T. Minami, Nature, 354, 217-218 (1991).

13) J. C. Boivin and G. Mairesse, Chem. Mater., 10, 28702888 (1998).

14) O. Smirnova, N. Kumada, Y. Yonesaki and N. Kinomura, Electrochem. Commun., 10, 485-487 (2008).

15) H. M. M. M. Arachchige, D. Zappa, N. Poli, N. Gunawardhana and E. Comini, Sensor. Actuat. B-Chem., 269, 331-339 (2018).

16) J. Sunarso, S. Baumann, J. M. Serra, W. A. Meulenberg, S. Liu, Y. S. Lin and J. C. Diniz da Costa, J. Membrane
Sci., 320, 13-41 (2008).

17) Y. Ren, Y. Shen, Y. Lin and C. Nan, Electrochem. Commun., 57, 27-30 (2015).

18) M. Salazar, D. A. Berry, T. H. Gardner, D. Shekhawat and D. Floyd, Appl. Catal. A-Gen., 310, 54-60 (2006).

19) A. V. Shlyakhtina, K. S. Pigalskiy, D. A. Belov, N. V. Lyskov, E. P. Kharitonova, I. V. Kolbanev, A. B. Borunova, O. K. Karyagina, E. M. Sadovskaya, V. A. Sadykov and N. F. Eremeev, Dalton T., 47, 2376-2392 (2018).

20) A. V. Shlyakhtina, D. A. Belov, K. S. Pigalskiy, A. N. Shchegolikhin, I. V. Kolbanev and O. K. Karyagina, Mater. Res. Bull., 49, 625-632 (2014).

21) L. Minervini, R. W. Grimes and K. E. Sickafus, J. Am. Ceram. Soc., 83, 1873-1878 (2000).

22) M. Saiduzzaman, T. Takei, S. Yanagida, N. Kumada, H. Das, H. Kyokane, S. Wakazaki, M. Azuma, C. Moriyoshi and Y. Kuroiwa, Inorg. Chem., 58, 17591763 (2019).

23) J. Lian, L. Wang, J. Chen, K. Sun, R. C. Ewing, J. M. Farmer and L. A. Boatner, Acta Materialia, 51, 1493 1502 (2003).

24) F. Izumi and K. Momma, Solid State Phenom., 130, 1520 (2007).

25) J. Grins, M. Nygren and T. Wallin, Mater. Res. Bull., 15, 53-61 (1980).

26) J. Isasi, M. L. Lopez, M. L. Veiga and C. Pica, Solid State Ionics, 89, 321-326 (1996).

27) R. Muduli, R. Pattanayak, S. Kumar, S. K. Kar, P. Kumar, S. Panigrahi and R. K. Panda, J. Alloy. Compd., 656, 33-44 (2016).

28) J. B. Goodenough, H. Y. Hong and J. A. Kafalas, Mater. Res. Bull., 11, 203-220 (1976).

29) A. D. English, A. W. Sleight, J. L. Fourquet and R. De Pape, Mater. Res. Bull., 15, 1727-1735 (1980). 